\title{
Lo sublime en la anti-sublime estética de lo cotidiano
}

\section{The sublime in the anti-sublime aesthetics of everyday life}

\author{
MARÍA JESÚS GODOY DOMÍNGUEZ \\ Universidad de Sevilla (España)
}

recibido: 19.05 .2018

aceptado: 26.11 .2018

\section{RESUMEN}

Este trabajo pretende aproximar dos realidades aparentemente contrapuestas como son la experiencia romántica de lo sublime y la emergente estética de lo cotidiano. Pero quiere hacerlo desde un enfoque distinto del de Thomas Leddy, que basado en el carácter extraordinario de los objetos y procesos normales de la vida, acaba haciendo de lo irrelevante diario, algo grande y atemorizante. Para nosotros, la experiencia sublime de lo cotidiano exige tomar la cotidianeidad como pura cotidianeidad, según aparece en Yuriko Saito. Esto lleva a fijarse en aspectos distintos de los establecidos por la estética moderna para lo sublime, como el sentimiento de asombro y la pequeñez, con los que se traza aquí un recorrido histórico alternativo para esta experiencia a través de pensadores como Burke, Schopenhauer, Ortega y Gasset y Carolyn Korsmeyer.

PALABRAS CLAVE

LO SUBLIME; ESTÉTICA DE LO COTIDIANO; LO SUBLIME COTIDIANO; ESTÉTICA MODERNA; ESTÉTICA CONTEMPORÁNEA

\section{ABSTRACT}

In this paper, we try to approach two apparently opposed realities, such as the Romantic experience of the sublime and the emergent aesthetics of everyday life. However, we want to apply a different point of view from that of Thomas Leddy. For this author, there are extraordinary traits in ordinary objects and experiences, so the irrelevant things in daily life become big and frightening. For us, the sublime experience of everyday life involves taking the everydayness as pure everydayness, as it is proposed by Yuriko Saito. It requires paying more attention to different aspects than those fixed by modern aesthetics for the sublime, such as the emotion of astonishment and smallness. With these two features, we draw 
another historical path for this aesthetic experience thanks to thinkers like Burke, Schopenhauer, Ortega y Gasset and Carolyn Korsmeyer.

KEYWORDS

\section{THE SUBLIME; EVERYDAY AESTHETICS; EVERYDAY SUBLIME; MODERN AESTHETICS; CONTEMPORARY AESTHETICS}

\section{TEST DE (IN)COMPATIBILIDAD}

EN PRINCIPIO, el intento de aproximación de dos realidades contrapuestas como la experiencia estética de lo sublime, por un lado, y la estética de lo cotidiano, por otro, sería un esfuerzo vano, por no decir condenado de antemano al fracaso. Es imposible conciliar - dicta la lógica más elementaldos realidades que, por propia definición y en fidelidad a sus respectivas épocas de surgimiento, poseen objetivos dispares: en el caso de lo sublime, como experiencia típicamente romántica-cuyos orígenes se remontarían, sin embargo, hasta la antigua Grecia ${ }^{1}$-, el fin es que el sujeto se desprenda de su finita dimensión sensible para alcanzar lo infinito y suprasensible, se eleve sobre su naturaleza corpórea y material y tome conciencia de su superioridad espiritual -racional y moral- frente al objeto desmesurado que lo amenaza físicamente y lo reduce prácticamente a la nada; en la estética de lo cotidiano, rama emergente de la disciplina estética surgida al calor de la sensibilidad postmoderna ${ }^{2}$, rige el descenso, por el contrario, a lo terrenal y lo mundano, a los objetos pequeños e insignificantes de todos los días en los que hasta hace poco no se había reparado y a las acciones banales donde éstos se hallan inmersos con vistas a su recuperación y, desde ese nuevo horizonte, a su revalorización como acreedores también de atención estética. La conclusión parece así fuera de toda duda: entre lo que apunta hacia arriba -lo sublime- y lo que apunta hacia abajo -todo un anti-sublime, como lo sería lo intrascendente y rutinario- sólo hay una

1 Aunque el autor del primer tratado sobre lo sublime, Longino, es ciertamente de época helenística (hacia mediados del siglo I d. C.), para Saint Girons es, sin embargo, un autor más moderno que antiguo, al no haber sido realmente conocido hasta el siglo XVI, cuando el humanista Francesco Robortello, exhumando su texto original, hizo posible su circulación posterior por toda Europa (Saint Girons, 2008: 62-63 y 90).

2 Sólo desde el descreimiento y la puesta en solfa postmoderna de los grandes absolutos modernos puede entenderse la emergencia de nuevos discursos como éste, alejados de los centros habituales de poder, con los que dar voz y visibilidad a aquello que tradicionalmente no las había tenido. 
incompatibilidad manifiesta.

Aun así, es posible mencionar una primera tentativa de confluencia por parte de uno de los valedores principales de la estética de lo cotidiano a día de hoy, como es Thomas Leddy (2012). Lo que proponemos aquí es justamente una nueva formulación de esta paradoja que parece ser lo sublime cotidiano, pues la formulación de Leddy, basada en su tesis sobre la experiencia extraordinaria de los objetos y procesos normales de la vida, acaba ciñéndose al modelo ilustrado de lo sublime y, por eso, lo pequeño e insustancial deviene al final grande y atemorizante. En contraste con ello, para nosotros, la teorización de lo sublime cotidiano pasa, en primer lugar, por tomar la cotidianeidad históricamente negada como pura cotidianeidad, esto es, en su carácter inferior y vulgar, una cotidianeidad inofensiva y anodina, como aparece en otros portavoces de la misma corriente estética, como Yuriko Saito (2007) o Arto Haapala (2004). Pero pasa también y, muy especialmente, por repensar el sentimiento de lo sublime, por hacer valer unas características distintas de las encumbradas por la tradición moderna -aquella que con epicentro en Kant instauró lo gigantesco y terrorífico como medida estándar- y, desde ahí, incluso por plantear un recorrido histórico para esta experiencia, si no alternativo, sí, al menos, complementario al que acabó imponiéndose.

Con estas miras, nuestra manera de proceder será la siguiente: empezaremos por explicar la propuesta de lo sublime cotidiano de Leddy; procederemos a continuación a exponer la nuestra, en su diferencia con la anterior, a partir de la noción de estética de lo cotidiano de Yuriko Saito y Arto Haapala fundamentalmente y con la ayuda además de Jane Forsey desde la órbita de la estética del diseño (2013a) ${ }^{3}$; finalmente y con todo ello, nos aventuraremos a trazar ese itinerario paralelo para lo sublime -a apuntarlo, más bien-, acudiendo a los propios argumentos del predecesor de Kant y mentor, junto a él, de la reflexión estética moderna de lo sublime, como fue Edmund Burke, pero también a los de Schopenhauer, Ortega y Gasset y, en nombre de la estética más actual, a los de Carolyn Korsmeyer.

\footnotetext{
3 Esta estética la plantea, no obstante, la autora como una crítica y, a la vez, una propuesta de concreción de la estética de lo cotidiano, a la que reprocha, entre otras cosas, su falta de rigor teórico y su excesivo abigarramiento de contenidos (Forsey, 2013b: 193-243).
} 


\section{II. ¿UN SUBLIME COTIDIANO EXTRAORDINARIO?}

Para abordar los planteamientos de Leddy sobre lo sublime cotidiano, es preciso aclarar previamente en qué consiste la variante de la estética de lo cotidiano en la que se inscribe el esteta norteamericano de las dos que ha distinguido Chris Dowling (2010) en ella, la fuerte y la débil. Según Dowling, la variante «débil» es la que cree posible ajustar los conceptos estéticos, de inspiración eminentemente artística, a los objetos y acciones de la vida diaria, no-artísticos por tanto, que extraídos de sus contextos funcionales, quedan sometidos a los mismos parámetros que han venido regulando el arte a lo largo de los dos últimos siglos, los que hicieron de él algo extraño, diferente e inusual. La variante «fuerte» defiende, en cambio, la necesidad de afrontar los objetos y actividades comunes como lo que realmente son, objetos y actividades nada especiales, como no lo son ni una cuchara, ni el hacer la colada por ejemplo. Tiende a eludir así la influencia del discurso estético moderno, que guiado por el paradigma artístico, ha buscado preservar el carácter único y singular de la experiencia estética, la actitud desinteresada que estableciera Kant para ella al escindir la belleza libre de la adherente (2001: \$16,164-167). Si algo tiene claro esta variante de la estética de lo cotidiano es que la apreciación estética tiene que poder integrarse en la utilidad y normalidad de la vida; o por decirlo a la manera de Yuriko Saito (2007: 26), que valorar la belleza pura de un utensilio, separarlo quirúrgicamente de su función, aun siendo de interés en alguna circunstancia, no deja de ser algo completamente artificial.

A diferencia de Saito, Haapala y Forsey, pero al igual que Dowling, Leddy se adhiere a la opción «débil», fruto de lo cual entiende que cuando dedicamos atención estética a un objeto corriente lo desposeemos automáticamente de su cotidianeidad y lo investimos de la excepcionalidad de la que en un primer momento carecía. Es decir, considera inviable acercarse estéticamente a lo cotidiano sin volverlo extraordinario (Leddy, 2012: $121)$, sin que ese acercamiento no sea como el que tiene lugar en el arte (112). De hecho, para Leddy lo cotidiano es nimio y aburrido, de escasa entidad, hasta que deviene estético transformándose en algo parecido a una obra artística y, por ende, importante. Dicha transformación se produce porque el objeto se inviste de eso que el autor, apropiándose del término que acuñara Benjamin, denomina «aura» y que hace que salga del ámbito de lo inadvertido y entre en el de lo notable y llamativo. Su manera 
de concebir el aura es distinta, por tanto, según Leddy, de la de Benjamin: no es ninguna propiedad intrínseca del objeto, sino una propiedad fenomenológica que adquiere éste en nuestra interacción con él, cuando lo experimentamos de un modo particularmente intenso o dotándose de un «hondo significado con el que parece extenderse más allá de sí mismo» (Leddy, 2012: 116-117). Que un objeto dado tenga aura implica entonces varias cosas para nosotros, siguiendo a Leddy: que lo consideramos mayor de lo que en verdad es -rasgo que se acentúa sobremanera en lo sublime-, que irradia una especie de resplandor y que parece singularmente vívido y real. Por eso, le atribuimos propiedades estéticas con las que venimos a indicar que la experiencia que estamos teniendo es la del aura. Así, por ejemplo, cuando decimos que una silla es elegante o delicada es porque la estamos viendo diferente y cargada de sentido, no sólo respecto al resto de objetos, sino sobre todo respecto a las restantes sillas de alrededor. Afirmamos entonces que hemos experimentado estéticamente la silla porque hemos hecho de ella, la hemos convertido, en una obra de arte.

Esta experiencia adquiere además para Leddy distintos grados e intensidades que dependen, en última instancia, de la belleza. El autor habla así de un continuum estético que iría desde el nivel básico o primordial de experiencia, como cuando apreciamos el orden de una habitación, donde estamos por debajo del umbral de la belleza, hasta el nivel máximo, en que lo superamos y, a veces además con creces, como ocurre sin ir más lejos en lo sublime (Leddy, 2012: 142). Vinculado, por supuesto, en Leddy a la noción de aura, es indeferente si este sentimiento viene inducido por un objeto insólito y superior como el artístico o por uno llano y sencillo, pues acaba adquiriendo de todos modos y, según lo que hemos visto, su mismo peso y notoriedad. No en vano, antes de desarrollar su teoría, arremete expresamente el autor contra una versión actual de esta experiencia, como es la de Arnold Berleant -representante también de la estética de lo cotidiano ${ }^{4}$-, quien bebiendo en lo sublime postmoderno de Lyotard, enuncia un «sublime negativo» que identifica con el gran parque de atracciones de Disneylandia ${ }^{5}$. Por este sublime entiende la misma ex-

4 A la manera, en su caso, de una estética ecológica o medioambiental.

5 En Living in the Landscape: towards an Aesthetics of Environment, de 1997. Respecto a Lyotard, la representación de lo irrepresentable en lo sublime -tema central en los cuatro grandes pensadores de lo sublime postmoderno, como son, además del propio Lyotard, Kristeva, Deleuze y Jameson- es una representación, para él, negativa, porque la incapaci- 
periencia, con el mismo concepto de magnitud inconmensurable, pero sin el momento clave de elevación espiritual que ha venido acompañándola desde sus remotos orígenes griegos -segundo momento, en la moderna explicación kantiana ${ }^{6}$-; un sublime terrenal o «falso sublime» donde las cosas, limitándose a sí mismas, no van más allá. La crítica en Leddy tiene que ver con que, para él, que lo sublime se relacione, en nuestro tiempo, con lo mundano -que exista, de hecho, un sublime cotidiano, como sostenemos aquí- no significa que no haya en él trascendencia; la hay, sólo que desde otros parámetros, no necesariamente ligada ya a las alturas o a una deidad suprema ${ }^{7}$. Para nosotros, vaya por delante, en lo sublime cotidiano hay también trascendencia, de «bajos vuelos» como en Leddy, pero -y ésta sería la novedad, frente a Leddy y frente a la misma Saito, reacia al menor resquicio de sofisticación en la experiencia estética de lo cotidiano (2007: 212)-, desde la pequeñez y la minucia más absoluta.

Para demostrar su teoría, el filósofo acude a una serie de autores que de un modo u otro y, a su juicio, la refrendarían; también, a la práctica de meditación e iluminación zen para alcanzar el nirvana -la trascendencia aquí estaría bastante clara-, motivada por cosas fútiles como una gota de agua, a la que le faltaría, no obstante, el miedo o el dolor incorporados a lo sublime por la estética moderna occidental ${ }^{8}$. En el apartado ya de autores, se sirve, por ejemplo, de Marcel Proust en su célebre pasaje de la magdalena ${ }^{9}$, donde la trivialidad del objeto -un simple comestible- es la que provoca la experiencia inconfundible de lo sublime, la que rememorando momentos del pasado permite tomar conciencia in extremis de la condición

dad de la imaginación para ofrecer una representación adecuada a la idea irrepresentable de lo absoluto, permite sentir la presencia de esa idea por el fallo precisamente de dicha facultad (Johnson, 2012: 118-131).

6 Según Kant, dos momentos, prácticamente superpuestos, conforman la experiencia de lo sublime: uno de repulsión y otro, de atracción; uno, puramente afectivo y otro, racional; el uno, doloroso y el otro, placentero (2001: \$27).

7 Es la idea de trascendencia, dice Leddy, que los sujetos no creyentes como él -así se declara a sí mismo el autor (2012: 249)- pueden llegar a tener en un mundo a-confesional como el nuestro (256).

8 Siendo Burke el pionero, como evidencia la siguiente cita suya: «Todo lo adecuado para excitar las ideas de dolor y peligro, es decir, todo lo que es de algún modo terrible, o se relaciona con objetos terribles, o actúa de manera análoga al terror, es fuente de lo sublime» (2010: 29).

9 Dentro de su obra En busca del tiempo perdido, de 1913. 
mortal humana y la que acaba turbando el ánimo con ello; el problema, según Leddy, es que no se sabe a ciencia cierta si lo que hay aquí es realmente un sublime cotidiano o, quizás, pensamientos sublimes generados por lo cotidiano. Otro autor al que recurre es Edward Bullough, uno de los grandes promotores de la distancia estética - del carácter separado, sagrado y engrandecido, por tanto, del objeto artístico- ${ }^{10}$, quien supo advertir igualmente que lo sublime se relaciona antes con el hallazgo de un lado insospechado de las cosas cercanas, con sacarlas de su engranaje práctico acostumbrado y revestirlas de hondo significado, que con sucesos dramáticos o espectaculares; cosas, como el efecto de niebla en el mar -dentro de lo cotidiano para Leddy (2012: 245), como parte del tiempo y la meteorología en general, omnipresentes en nuestras vidas ${ }^{11}$, donde la imaginación descubre formas insólitas, crea un mundo paralelo -en el ejemplo de la niebla y, siguiendo a Bullough, permite ver sirenas a las que poder tocar con sólo alargar la mano y traspasar así la espesura blanca-, cuyo contenido no sería, sin embargo, todo lo trascendente que cabría esperar.

En quienes confía principalmente Leddy para articular su visión de lo sublime cotidiano son Heidegger y Nietzsche. La elección del primero se debe a su conocido análisis del par de botas que pintara van Gogh ${ }^{12}$, donde de manera indirecta, o por medio del arte, se aborda el tema de lo cotidiano, materializado aquí, obviamente, en las botas representadas. A pesar de su humildad o debido precisamente a ella, dichas botas encierran para Heidegger un profundo contenido existencial, relativo a la vida de su portador imaginario que el filósofo presenta como ser-hacia-la-muerte; de ahí su nexo de unión con lo sublime. Leddy está convencido, efectivamente, de que animándonos a contemplar los zapatos con ese trasfondo, invitándonos a imaginar a la campesina que los usa, ya no como mujer trabajadora, sino como alguien arrojado al mundo que tarde o temprano morirá, Heidegger nos coloca al borde del precipicio, nos hace «rozar el abismo» (Leddy, 2012: 250); nos infunde, en definitiva, el miedo y el desasosiego que decretara Burke para lo sublime, al recordarnos el drama de la muerte al que todos estamos abocados. De ello infiere Leddy que lo más prosaico - un par de botas harapientas- puede proporcionar una expe-

10 En La distancia psíquica, de 1912.

11 Leddy sigue aquí a Saito (2007).

12 En su ensayo de 1935, El origen de la obra de arte. 
riencia inefable, de revelación, como aquí, de un destino para el que nunca estamos suficientemente preparados; pero lo hace, en tanto en cuanto nuestra mirada -amparada en la de Heiddeger- lo libera de ese prosaísmo, del universo utilitario e inocuo al que pertenece, y le atribuye el lirismo y la grandeza de lo estéticamente memorable.

Respecto a Nietzsche, Leddy rescata de su pensamiento la idea de lo dionisíaco y el hombre trágico ${ }^{13}$; en general, el dualismo entre lo apolíneo y lo dionisíaco en la tragedia griega, que en Nietzsche y para Leddy, es totalmente sublime. En el seno de esa dicotomía, Apolo, dios de la luz, encarna la razón y la cordura, aunque también el sueño -aquí ve expresado Leddy lo cotidiano, dado que los sueños suceden todos los días- y la ilusión o el engaño, asociados, en el universo ático, a los dioses olímpicos, gracias a los cuales los antiguos griegos dieron sentido a sus vidas. Por su parte, Dioniso, dios del vino, es quien representando el desenfreno de los sentidos, el éxtasis y la enajenación, desvela la verdad de la existencia; quien llevando hasta la conciencia lo inevitable del sufrimiento y la muerte, hace del hombre un ser trágico -temeroso, al fin y al cabo, de la muerte, volviendo a Burke-, pero al mismo tiempo un ser valiente, capaz de plantar cara a esa realidad. Si bien el hecho de ver apolíneamente el mundo como si fuera un sueño no sería en sí mismo sublime, puntualiza Leddy (2012: 253-4), sí lo sería cuando ese sueño muestra, de forma dionisíaca, lo que se oculta detrás; o remitiéndonos a la noción de aura de Leddy, cuando el hecho rutinario de soñar se reviste de excepcionalidad y expande así su tamaño y su alcance.

Al final, Leddy acaba poniendo en relación el binomio nietzscheano con la Caja Brillo de Andy Warhol (1964), a fin de desmentir la lectura que Danto hiciera de ella ${ }^{14}$, a partir del término «transfiguración» tomado del propio Nietzsche. En ese sentido, la obra de Warhol, con su transfiguración del lugar común, en expresión ya de Danto, o indistinción entre el arte y el no-arte, más que un gesto apolíneo con el que racionalizar y separar dominios, que es como aparece en Danto, habría sido un gesto dionisíaco con el que hacer desaparecer precisamente esa diferencia. Sin embargo y aunque Leddy insiste en que con ello Warhol afirmó la realidad humilde de todos los días (2012: 255), lo que se percibe realmente es que

13 En El nacimiento de la tragedia, de 1872.

14 En su obra La transfiguración del lugar común, de 1981. 
volviendo la caja de detergente del supermercado indiscernible de la pieza de un museo, el artista la habría sustraído de esa realidad, del ámbito de lo indiferente -que habría negado así, en vez de afirmado como dice Leddy-, y dentro ya de lo diferente y elevado, le habría otorgado fondo y sustancia; en resumidas cuentas, que al transformar dicha caja en algo más que una simple caja, habría hecho posible experimentarla de modo sublime.

\section{UN SUBLIME COTIDIANO GENUINAMENTE COTIDIANO}

Leddy se suma a la variante «débil» de la estética de lo cotidiano en la creencia de que el mero intento de valorar estéticamente lo rutinario lo empuja en dirección a lo extraordinario ${ }^{15}$. Desde esta perspectiva, ya no sería tan disparatado hacer concurrir una experiencia, dentro de lo extraordinario, particularmente extraordinaria como la de lo sublime, con las cosas ramplonas del día a día. Sí lo sigue siendo, en cambio, cuando esas cosas permanecen en su contexto práctico originario -no son nada extraordinarias entonces- $\mathrm{y}$ es en él donde tiene lugar la valoración estética, como argumenta la variante «fuerte»; cuando esa variante evita, de hecho, concederles el estatuto honorífico del arte que sólo consigue falsear la realidad, como ha denunciado por boca de Yuriko Saito ${ }^{16}$. No obstante, es lo que nos proponemos demostrar, que puede existir la experiencia de lo sublime sin desposeer a los objetos de su naturaleza instrumental, sin ascenderlos de categoría para entendernos, que es lo que hace, al fin y al cabo, Leddy llevándolos al terreno de lo exclusivo y lo poco común. Si acaso y en este pretendido aferramiento a lo mundano, es lo sublime lo que menguaría en este caso de categoría, lo que resultaría hasta cierto punto degradado, para ponerse al mismo nivel de aquello para lo que nunca antes había existido atención estética, aunque sin dejar de ser por ello sublime y de proporcionar, en consecuencia, una vivencia placentera de conjunto ${ }^{17}$.

Una iniciativa para superar el modelo artístico de excepcionalidad que aboca a los objetos normales a renunciar a su normalidad intrínseca ha sido la de Arto Haapala (2004), en la que se reprueba abiertamente la

15 Lo creyó inicialmente, en 2005 (18), y lo sigue manteniendo en 2012.

16 «I believe this art-centered approach misconstrues the nature of our aesthetic lives, as well as unduly limits its scope» (2007: 15).

17 Como lo sublime se vale del dolor, y por ende del miedo, para llegar al placer, la vivencia final es placentera aunque inicialmente pueda resultar dolorosa y desabrida. 
noción de «extrañeza». Su interés para nosotros reside realmente en la matización introducida después por Jane Forsey (2013a) desde la esfera del diseño de productos. La extrañeza de Haapala se asemeja bastante a la idea de aura de Leddy, al tratarse también de una propiedad fenomenológica que adquieren las cosas en nuestra interacción con ellas, o mejor aquí, en nuestra falta de interacción, porque tendemos a considerar algo extraño cuando lo desconocemos o carecemos de contacto con él. Todo lo contrario ocurre cuando lo rozamos, cuando forma parte de nuestro entorno y de nuestras vidas, que hace que se vuelva casero y familiar. En aras de esta familiaridad, recupera el teórico finlandés el análisis existencial heideggeriano de una herramienta como el martillo (cfr. Heidegger, 1927), que funcionando correctamente, pasa desapercibido ante nuestros ojos; es decir, que respondiendo al uso para el que está destinado, a su ser-en-el-mundo, resulta completamente invisible, desaparece en su contexto práctico, de lo familiar que es para nosotros. Sólo cuando deja de funcionar, recupera su visibilidad o reparamos en su presencia, que advertimos así particularmente llamativa o extraña, sinónimo aquí de privada de uso. Pero si por algo acude Haapala al pensador alemán es porque quiere devolver, hemos dicho, la experiencia estética de un utensilio como el martillo al ámbito de la familiaridad y, de paso, desechar la extrañeza a la que se entrega por entero Leddy. Vincula así la familiaridad al proceso, nuevamente heideggeriano, de «crear-hogan», de instalarse en un lugar concreto y fundar un sentido de pertenencia al mismo trabando lazos con él.

Dentro de ese entorno familiar y próximo, la experiencia estética es presentada de manera negativa por Haapala; exactamente, como la tranquilidad que se obtiene de la falta - «the lacking»- de requerimiento visual, auditivo, o del tipo sensible que sea, a nuestro alrededor (Haapala, 2004: 52). Según describe el autor, es como si lo cotidiano procurase ya placer mediante la sensación de confort y estabilidad que conlleva, sensación de saber todo a salvo y bajo control; luego sin necesidad de abandonar su contexto, sólo por su familiaridad para nosotros, que nos da un cierto sentido de estar realmente en casa. El problema, para Forsey, es la idea equivocada de experiencia estética que se detecta en este discurso (2013a: 242): unida, por un lado, a la sensación de bienestar y comodidad, tendría un aspecto corporal -como lo tienen otras muchas experiencias cotidianas como un baño de agua caliente o un sofá acogedor- que escapa totalmente 
al placer estético; identificada, por otro lado, con la satisfacción que sentimos al llegar a casa y encontrar las cosas como esperamos encontrarlas, según un sentido de orden y seguridad más o menos previsible, se investiría de una connotación ético-existencial, que aun proveyéndonos de identidad, tampoco se ajusta a lo puramente estético. Pese a todo, Haapala se las arregla al final, dice Forsey, para dirigir nuestra atención hacia algo que sin llamar en absoluto, paradójicamente, la atención, simplemente por estar ahí, se supone que ha de brindarnos una experiencia estética.

Para superar esta deficiencia, Forsey propone una solución a medio camino entre lo extraño y excepcional de Leddy -lo exótico, como ella dice- y lo familiar y común de Haapala -lo inadvertido, en definitiva-, de la que nos valdremos para nuestro propósito. Sostiene Forsey que aun coincidiendo con Leddy y Haapala en que los útiles domésticos tienden a desaparecer en su contexto instrumental, a volverse invisibles bajo nuestra mirada, no es sólo cuando dejan de funcionar cuando se hacen notar, según estableciera Heidegger. También nos percatamos de ellos cuando funcionan extremadamente bien, cuando cumplen su cometido con un cuidado, una facilidad o una elegancia que capta rápidamente nuestra atención ${ }^{18}$. La apreciación estética del objeto tiene que ver, en este caso, con su capacidad para superar todas las expectativas, que sin embargo no hacen de él algo extraño en el sentido artístico: por mucho que el objeto logre sobresalir, lo hace entre los de su mismo género, los que son utensilios como él, por lo que, ni abandona su entorno funcional, ni pasa a ser una obra de arte. Sigue siendo el mismo objeto de siempre, sigue sirviendo, por ejemplo, para sentarse -si hablamos de la silla de antes- o para cortar -si es el martillo de Heidegger-, sólo que en virtud de esa circunstancia reclama además atención estética. De modo análogo, si la silla tiene el asiento hundido o el martillo pesa demasiado pueden ser valorados estéticamente, pero ya no en sentido laudatorio, sino reprobatorio. Se trata así de una valoración estética que no se despoja, en ningún momento, de la utilidad del

18 Estas cualidades - cuidadoso, elegante-, junto a otras -respetuoso, considerado, sensible...-, todas ellas relacionadas de un modo u otro con valores morales, dice Saito que cuando son empleadas para evaluar objetos utilitarios, dan lugar a los juicios «estético-morales», que son estéticos al originarse en nuestra experiencia sensible del objeto y morales, como decisivos para alcanzar una sociedad y un mundo más civilizado y para mejorar, en suma, nuestras vidas (Saito, 2007: 207-213). 
objeto; es más, que tiene en ella su razón de ser. Forsey es rotunda al respecto: «cumplir con su función es el requisito mínimo para que un objeto utilitario puede ser candidato para la apreciación estética» (2013a: 243) ${ }^{19}$.

\section{Otro sublime}

Nuestra argumentación entronca con la de Forsey al entender que cuando un utensilio es digno de apreciación estética, de signo positivo además o favorable, que es en la que Forsey pone particularmente el acento, o sea, cuando reparamos en él por su excelente funcionamiento, aviva en nosotros un sentimiento de asombro o admiración, susceptible de ponerse en relación con la experiencia de lo sublime; pero lo sublime en el sentido heterodoxo que proponemos aquí, disidente tanto del modelo sugerido por Leddy para la estética de lo cotidiano, fundamentado en el carácter extraordinario de la experiencia, como, más importante aún, disidente del modelo de ascendencia ilustrada, primero, y romántica después, que despreciara lo pequeño y lo minúsculo en aras de lo mayúsculo y colosal. Por eso, aunque en desacuerdo inicialmente con Saito -quien se muestra reticente, hemos dicho, a que la experiencia estética de lo cotidiano albergue el tipo de ideas exquisitas y elevadas del arte-, pensamos que en realidad no lo estamos tanto, porque la vivencia de lo sublime que en este caso defendemos, no sólo no nos desconecta del entorno funcional donde nos movemos a diario, sino que nos une aún más a él, pues es a él, a fin de cuentas, al que se la debemos.

Respecto a la primera disidencia, el mismo Leddy ha indicado que el efecto de encanto o fascinación, normalmente provocado por el arte y la naturaleza, puede estarlo también por objetos y situaciones menos grandilocuentes - por el hecho incluso de tirar la basura, como refiere el autor evocando una de sus tiras cómicas favoritas (Leddy, 2015)-, aunque procurando siempre el máximo impacto estético y emulando por eso el comportamiento de los objetos distinguidos y refinados -en el ejemplo de la basura, haciendo que el protagonista que la porta se detenga un momento para contemplar el cielo y las estrellas y se pregunte por la vida

19 En lugar de «objeto utilitario» («utilitarian object»), la autora utiliza la expresión «objeto de diseño o diseñado» («design objet»). Como esta expresión -«de diseño»- tiene la connotación, añadida en español, de objeto «de autor», nos hemos decantado por una traducción menos fiel o literal. 
en general, como haría ante un cuadro de Friedrich por ejemplo o ante el mismo firmamento en una noche despejada-. Leddy admite así el cambio de estímulo, pero no de experiencia, que continúa siendo inusitada; una experiencia, arguye el autor, que nos saca del curso normal de la vida porque nos hace tomar una actitud diferente ante ella; una experiencia, en definitiva, extraordinaria -como lo sería la acción misma de tirar la basura, que para Leddy representa, a pesar de su carácter vulgar y mundano, un momento irrepetible, el «momento basura»-. Instalado en esa excepcionalidad, le resulta muy fácil dar el paso siguiente, vincular la admiración a lo sublime: sin limitarse específicamente a este afecto, lo sublime lo llevaría, de todos modos, incorporado y asumiría así un cariz más amplio que el que le fuera asignado en la estética moderna.

En nuestro caso, aun compartiendo con Leddy que el asombro ensancha y hace crecer la experiencia de lo sublime respecto a su restringida acepción enciclopedista, discrepamos en que el momento estético articulado por este estado afectivo tenga que ser por fuerza un momento «fuera de serie» -nos adherimos así a la postura de Saito-; al fin y al cabo, que un objeto determinado cumpla exquisitamente con su función, nos hace detenernos en él, nos hace aprehenderlo, quizás como nunca antes lo habíamos hecho porque despierta de modo inesperado nuestra curiosidad, pero lo hace por el certero ensamblaje de dicha función con la forma, o en nuestra relación instrumental con él, de la que en ningún caso nos desprendemos como recalca Forsey, porque es la que nos lleva hasta esa feliz circunstancia ${ }^{20}$. La aprehensión estética se desarrolla así en unos términos bastante ordinarios, lo que no excluye un trasfondo ético, como veremos más adelante ${ }^{21}$.

La primera disidencia nos lleva a la segunda, porque cuando Leddy

20 Dice la autora que sólo si soy bebedor de café puedo llegar a apreciar estéticamente una cafetera. Si no lo soy, la veré como un objeto ajeno a mí y seré incapaz de darle ese valor adicional (2013a: 243).

21 Máxime, teniendo en cuenta la reciente caracterización psicológica del asombro como una de las llamadas emociones auto-trascendentes, que son aquellas emociones que al igual que la gratitud y la compasión predisponen al individuo a dejar apartadas sus necesidades personales y a preocuparse por las de los demás; incitan así al cuidado, la cooperación y el benestar general (Stellar et al, 2017). Según esta concepción, el asombro, haciendo salir de uno mismo para dedicarse al otro, sería en sí misma una emoción eminentemente social y profundamente ética, lo que refrendaría, ya de entrada, nuestra posición en este estudio. 
sugiere el enlace del asombro con lo sublime, se queda en eso, en mera sugerencia o insinuación, no llegando a profundizar entonces en lo que supone para esta experiencia estética esa otra reacción afectiva que viene a sustituir al miedo y el terror habituales, y los objetos baladíes de los que nos venimos ocupando. Empezando por el asombro, que éste sea el sentimiento dominante en lo sublime no es ninguna novedad, pues el mismo Burke que consagrara el «horror delicioso» como su principal seña de identidad (2010: 171), hizo constar también el papel de esta emoción, y no precisamente como un afecto menor o secundario, al plantearlo como una especie de parálisis donde la mente y el sujeto en general queda literalmente absorbido por el objeto que la provoca; de ahí el veredicto del irlandés: «el asombro, como he dicho, es el efecto de lo sublime en su grado más alto» (Burke, 2010: 85) ${ }^{22}$. Varias razones sustentan esta afirmación a lo largo del ensayo que dedica el pensador a este asunto: una es que hasta en una afección inicialmente tan poco alarmante y perturbadora como ésta al menos, en comparación con el pánico y el terror-, está presente el miedo como principio rector de lo sublime, formando entre ellas una poderosa entente; no por casualidad, arguye Burke, son numerosas las lenguas donde el mismo término sirve para designar miedo y fascinación, como ocurre con el verbo stupeo del latín, que significando estado de ánimo asombrado, acoge también la idea de terror (2010: 86) ${ }^{23}$. Otra razón es que no hay sublime sin modificación de poder, esto es, sin un agente sometedor que haga ostentación de su fuerza y uno sometido dispuesto a conferirle esa superioridad (Burke, 2010: 93); esta renuncia en toda regla o desposesión de la propia voluntad se extiende igualmente al asombro, donde lo que hacemos, después de todo, es rendirnos ante lo que nos provoca esa gran estupefacción: «nos sometemos a lo que admiramos» (Kant, 2001: 148).

22 Kant confirmará luego este parecer cuando al deslindar los ámbitos respectivos de lo bello y lo sublime, defina lo bello como un sentimiento positivo y de vida, y lo sublime, como un sentimiento negativo y de «suspensión momentánea de las facultades vitales» donde la satisfacción posterior «merece llamarse, no tanto placer positivo, como mejor, admiración o respeto, es decir, placer negativo» (Kant, 2001: \23, 184). Así, aunque Kant distinguirá lo sublime por el movimiento del espíritu frente a la contemplación reposada de lo bello $(\$ 24,187 ; \$ 27,200)$, dará cabida, al igual que Burke, a ese momento fugaz de inoperancia.

23 Esta mezcla de emociones volverá a aparecer en Kant, cuando aludiendo a quien visita por primera vez la iglesia de San Pedro del Vaticano en Roma, recalca el «estupor o especie de perplejidad que, según cuentan, se apodera del espectador» (Kant, 2001: §26, 193). 
Una última razón, que contradice, sin embargo, las anteriores, es que lo sublime, estimulado presuntamente por el miedo, puede darse del mismo modo sin él; puede ser activado por otras muchas sensaciones que, sin nada que ver ya con el peligro, provocan una exaltación de ánimo similar (2010: 165-6, 169).

De estas tres razones, las que mejor se ajustan a nuestro objetivo son la segunda y la tercera, pues aunque en lo sublime cotidiano haya claudicación por nuestra parte, subyugación si se quiere, al objeto que nos seduce y nos atrapa con su comportamiento ejemplar - esto sería con relación a la segunda-, ese arrebatamiento de la propia voluntad como dice Burke no se asemeja ni, menos aún, se confunde con el miedo -en referencia a la primera-, que quedaría en este caso al margen -de acuerdo con la tercera-, dado el carácter cercano y hogareño de los objetos implicados ${ }^{24}$. Lo sublime cotidiano sería así un sublime sin el terror preescrito por el propio Burke y refrendado después por $\mathrm{Kant}^{25}$, donde de todos modos nos sometemos a lo irrelevante del día a día que tanta impresión nos causa. A propósito de ello, vimos anteriormente la diferencia entre las modalidades «fuerte»y «débil» de la estética de lo cotidiano, que dependía de si la valoración estética respetaba la idiosincrasia práctica del objeto o si prescindía de ella al equipararlo al objeto artístico o a-funcional. Aplicando lo que acabamos de decir sobre el asombro a esta doble modalidad, podríamos establecer la siguiente máxima: en la variante «débil» de la estética de lo cotidiano, la de Leddy para nosotros, se daría paradójicamente una formulación «fuerte» de lo sublime, un sublime violento, ya que comporta miedo y terror; en Leddy sin ir más lejos, el miedo de saberse un ser-para-la-muerte, según la lectura de Heidegger del par de botas pintado por van Gogh a la que alude el autor, o el de descubrir la verdad trágica de la existencia a la manera dionisíaca de Nietzsche, recuperada también por el esteta norteamericano. Por su parte, en la variante «fuerte» de la estética de lo cotidiano, la que aquí hemos identificado con Saito, Haapala y Forsey, hallaríamos la formulación «débil» de lo sublime, un sublime relajado donde el asombro reemplaza al miedo, lo que no le impide seguir siendo sublime.

24 De no ser así, esto es, si lo cercano y hogareño despertara miedo, ya no estaríamos en el ámbito de lo sublime, sino en el de lo siniestro, como ha explicado muy bien Eugenio Trías (2001: 44-45).

25 Sobre todo, al desarrollar lo sublime matemático en la naturaleza, de la que asegura Kant que «su aspecto es tanto más atractivo cuanto más temible» (Kant, 2001: \$28, 204). 
Este sublime débil o rebajado, introducido por Burke hacia mediados del XVIII, tendría continuidad teórica, en las primeras décadas del XIX, con Schopenhauer (1987). En efecto, en su visión polarizada del mundo como voluntad y representación, el mundo como pulsión ciega sin motivo ni fundamento y el mundo de los fenómenos sujeto a las coordenadas espacio-temporales dadas por el principio de individuación, Schopenhauer dejó establecida una jerarquía para lo sublime que iba desde el grado mínimo, donde colindaba con lo bello - de hecho, era muy fácil el tránsito de una categoría a otra-, hasta el grado máximo en que era sublime en estado puro. En su nivel ínfimo o inferior, en eso que el filósofo llama «sublime pálido» (Schopenhauer, 1987: 165), el conocimiento se producía de manera similar al de lo bello, es decir, sin lucha con la voluntad -sin amenaza y $\sin$ miedo, por tanto-, a la que lograba apartar sin que la conciencia se diera cuenta. Como ejemplo, ponía un desierto infinito sin movimiento -en Schopenhauer, el tamaño sigue ajustado al ilustrado y, por ende, al romántico- como el de las enormes praderas norteamericanas, que al no ofrecer objeto alguno a la voluntad, sumía en un estado de contemplación pura y generaba hondos pensamientos, pero sin turbar nunca demasiado, limitándose a ser así un leve toque de sublime (Brady, 2013: 98). Pero en el nivel superior, el conocimiento se daba arrancándose con violencia y conscientemente a la voluntad -que amenazando con fiereza, aterrorizaba y despertaba auténtico pavor-, como ocurría ante la infinitud del universo, que al tiempo que soliviantaba, que hacía sentirse vencido de antemano en la refriega con él, permitía entender que en el fondo somos uno con ese enorme impulso volitivo.

A todo ello, añadiría Schopenhauer que los individuos «de sentir estético poco desarrollado y de imaginación apagada» (1987: 165) son capaces de acceder únicamente al sublime de grado más alto; habiendo asimilado aquí jerarquía a miedo, consideramos que la experiencia de lo sublime es obviamente más sencilla -más accesible a los sujetos de escasa sensibilidad estética de Schopenhauer- cuando responde a su descripción canónica, es decir, cuando la agitación de ánimo que produce es la del miedo, o sencillamente la que cabe esperar de acuerdo con la tradición; más resbaladiza y huidiza resulta, en cambio, cuando la experiencia es la de lo sublime en su grado más bajo, o sublime en otros términos, más plano y horizontal, o directamente, sublime sin miedo. 
Pero la disidencia del modelo estandarizado de lo sublime no sólo atañe al tipo de reacción afectiva; atañe igualmente al objeto causante de la experiencia, que resulta inofensivo en la medida en que se halla también muy lejos del exceso romántico. En ese sentido y como en el asombro, merece la pena rastrear en la estética moderna rasgos de este objeto, distintos de los que pasaron a la historia; concretamente un rasgo, que nos devuelve nuevamente a Burke: al recalar en la vastedad, dentro de su exposición de las múltiples propiedades incitadoras, según él, de lo sublime, especifica que el extremo opuesto de la pequeñez, aquello que define como «lo enano» (Burke, 2010: 196), figura también entre ellas ${ }^{26}$. Aclara, al respecto, que la pequeñez cae por lo general dentro del vasto dominio de la belleza, pero no lo extremadamente pequeño, que rara vez, por el contrario, puede considerarse bello. Habla entonces de «los prodigios de lo diminuto» (2010: 103), entre los que cita la infinita divisibilidad de la materia -infinita por la idea de sucesión y uniformidad que conlleva, que en Burke siempre es sublime- y los seres microscópicos que, minuciosamente organizados, nos maravillan sin cesar ${ }^{27}$. En ambos ejemplos como vemos, el asombro está inducido por el buen funcionamiento y la estructura meticulosa del ser o elemento en cuestión, por la dificultad que llevan pareja y por lo que no deja de ser así una «unidad perfecta» (Burke, 2010: 103) ${ }^{28}$.

Con el paso del tiempo, halleremos ideas hasta cierto punto parecidas en Ortega y Gasset, aun cuando sus preferencias estéticas fueran por otros derroteros, los de la belleza exactamente. Estas ideas se enmarcan en el rechazo que, a inicios del siglo XX y en un clima de progresivo abandono del idealismo romántico, profesa el filósofo hacia lo exuberante y excesivo,

$26 \mathrm{Al}$ advertir este aspecto en la teoría de lo sublime de Burke, Brady lo califica de «muy interesante» (2013: 26). La valoración obedece sin duda a la fricción que se produce en este punto entre Burke y Kant; para este último, la apreciación de lo grande va unida en nosotros siempre a un respeto, «así como a aquello que llamamos sencillamente pequeño unimos un desprecio» (Kant, 2001: \$25, 190).

27 Nótese que Burke alude expresamente aquí al asombro - habla de «maravillarse»-, no al miedo.

28 En recientes investigaciones psicológicas sobre el asombro y lo sublime, esta perfección, aunque aplicada a un objeto de reducidas dimensiones como aquí, nos devuelve a la idea de vastedad, pues en ella se percibe algo como mayor de lo que realmente es, y no necesariamente por su tamaño, sino por otro tipo de aspectos como la fama, la autoridad, el prestigio, la habilidad o el talento (Keltner y Haidt, 2003: 303). 
lo trascendente y espiritual ${ }^{29}$, encarnado para él en el hombre germano u hombre gótico, y su inclinación a la vez por lo modesto y mesurado, lo mundano y material que ve proyectado en el hombre mediterráneo u hombre hispano, especialmente en su arte y sensibilidad de tipo realista (Ortega y Gasset, 2004a: 435-436; 2004b: 773-781). Esto le lleva a alabar un cuadro como Las Meninas de Velázquez (1656), donde el pintor de reyes y papas, plasmó, sin embargo y en honor a la raza que como español circulaba por sus venas según Ortega, nada menos que el aire, «última y suprema insignificancia» (2004a: 447). Y al hacerlo, al poner el foco sobre lo minúsculo e imperceptible, sobre lo que desechamos y al mismo tiempo necesitamos perentoriamente para vivir -como ocurre, por cierto, con muchos de los utensilios que nos rodean-, Velázquez nos deslumbró con su maestría, pero sobre todo nos mostró otro sublime, el sublime que huyendo de desmesuras injustificadas busca el ser verdadero de las cosas; el que descendiendo hasta lo inferior e individualizándolo, le hace ganar en intensidad y fuerza expresiva. Para Ortega, Velázquez representa como nadie la creatividad artística española, que entregada a la presencia y actualidad de los objetos, los escenifica «en su rudeza material, en su individualidad, en su miseria y sordidez» (2004a: 446). En otras palabras, que por modestas y poco heroicas que fueran las cosas, el pintor las retrataba tal cual, en su austera realidad y es así como, sorprendentemente, las volvía sublimes; eso sí, sublime en el sentido pálido y rebajado de Schopenhauer, en el sobrio y modesto por el que se decanta también Ortega (Murcia Serrano, 2015: 377), que sin despegarse de lo que son esas cosas, de su nimiedad o su utilidad, es capaz de revelar también un hondo contenido de fondo, una trascendencia, tal y como venimos diciendo.

Para explicar esta trascendencia -recordemos, al estilo Leddy o mundanizada-, hemos de dirigirnos a la noción de héroe del propio Ortega, gestada dentro de su filosofía raciovitalista y de gran similitud, como veremos, con el espíritu subyacente a la variante «fuerte» de la estética de lo cotidiano. Este héroe, en tanto ser verdadero, no es un ningún héroe glorioso, protagonista de grandes gestas que quedan para siempre en la memoria, según el prototipo de héroe clásico o super-héroe, que diríamos hoy. El héroe en Ortega, lejos de un individuo con poderes sobrenaturales que

29 En Ortega, a diferencia de Leddy, estos dos términos se identifican. Leddy propone, como hemos visto, una trascendencia «menos elevada». 
arriesga su vida por un fin encomiable, es un sujeto sencillo - «todos, en varia medida, somos héroes», escribe el filósofo (Ortega y Gasset, 2004b: 754)-, ingenuo incluso, un anti-héroe, como lo es antes que nadie don Quijote. Las excéntricas y ridículas hazañas de este personaje, más propias del género cómico que del trágico donde habita el héroe stricto sensu (2004b: 818-822), informan, sin embargo, de la voluntad inquebrantable de perseverar en el propio ser. Y en eso consiste exactamente la heroicidad para el filósofo, la verdadera, en mantenerse fiel a uno mismo « «yo soy el que soy», dice en una ocasión don Quijote-, en no querer ser nada más que aquello que uno es y para lo que siente que ha nacido - en don Quijote, la voluntad y el proyecto existencial de la aventura (2004b: 816) -. En esa autenticidad de quien, insignificante y diminuto, se limita a ser él mismo; en la autenticidad de quien, con rasgos tan poco o nada épicos, se esfuerza en alcanzar lo que quiere, radica a su vez lo sublime comedido de Ortega; un sublime más bello que propiamente sublime ${ }^{30}$, porque su valor ético -que lo tiene, como sublime que es, y ésta es la prueba ${ }^{31}$ - se verifica, como en la belleza, aquí en la tierra, con los pies en el suelo, o con el individuo de carne y hueso -auténtico héroe-decidido a ser el hombre que es.

En este punto, regresamos a las observaciones de Forsey en que aseguraba que es posible apreciar estéticamente objetos utilitarios por su óptimo funcionamiento. Tal y como ella la presentaba, la valoración estética tenía como fin expreso, en ese caso, la utilidad del objeto, en su adecuación a la forma con la que éste estaba construido y diseñado - al peso, al material y al tamaño, entre otros muchos aspectos-, pero era la utilidad lo que hacía de reclamo, lo que permitía descubrir en ese objeto un algo, un plus, que escapaba al resto de objetos de su misma especie ${ }^{32}$. Si estas tesis de Forsey, las cruzamos ahora con los planteamientos raciovitalistas de Ortega, acabaremos de perfilar el nuestro: en la apreciación estética de lo cotidiano, el útil sigue siendo útil y, además, no se pretende otra cosa. Al contrario que en la experiencia extraordinaria de Leddy, donde el objeto utilitario, desgajado de su entorno funcional, es medido con el objeto artístico y as-

30 Según Murcia, lo sublime auténtico en Ortega es la belleza (Murcia Serrano, 2015: 379).

31 Valor ético, de ascendencia kantiana: «En realidad, sin desarrollo de ideas morales, lo que nosotros, preparados por la cultura, llamamos sublime, aparecerá al hombre rudo sólo como atemorizante» (Kant, 2001: \$29, 209).

32 Esta idea recorre de arriba abajo su Estética del diseño (2013b). 
cendido a su nivel, en esta otra experiencia, no tan selecta quizá, pero igual de noble y comprometida, el objeto sólo se mide con él mismo, con lo que puede llegar a ser y lo que cabe esperar de él en cuanto útil doméstico. El asombro desencadenante de lo sublime se produce así al comprobar que ha llegado a ser, ciertamente, lo que podía ser dentro de su categoría -«el objeto es el que es», diríamos versionando las palabras de don Quijote-; al certificar que, fiel a sí mismo, el objeto, al igual que el héroe de Ortega -anti-héroe, según lo que hemos visto-, ha logrado su meta existencial, ha hecho realidad al ideal práctico que moraba en su interior y para el que estaba destinado. El objeto se limita a ser él mismo, se reduce a su pequeñez, pero a través de esa limitación consigue precisamente trascenderla; porta un mensaje de autenticidad, de fidelidad a sí mismo y plenitud. Con razón, dice Ortega que el encuentro con lo mínimo, el apego a lo próximo y lo mundano, «da en nuestros pechos realidad y eficacia a lo sublime» (2004b: 756). Con razón, sostiene también Yuriko Saito que lo aparentemente insustancial y, hasta frívolo de nuestras vidas, contiene inimaginables efectos pragmáticos: políticos, sociales, ecológicos y, de especial interés para nosotros, éticos y existenciales (2007: 52).

Pero si se trata de un sublime degradado, ninguno como el que dibuja Carolyn Korsmeyer (2011), al hilo de su reciente restablecimiento estético del asco. Aun siendo así un sublime donde el estado afectivo en que se sume el sujeto es muy distinto del asombro, lo abordaremos también debido al tipo de objeto que pone en marcha la experiencia y al componente trascendental que, pese a todo, puede advertirse asimismo en ella.

Hasta ahora, nuestro discurso en torno a la estética de lo cotidiano nos ha situado ante un objeto cualquiera -un utensilio práctico, como caso paradigmático-, que hemos calificado de insignificante, mísero, vulgar y hasta de ridículo; un objeto que no sólo era inferior al objeto natural o artístico, el objeto único, diferente y grandioso que ha venido presidiendo la experiencia estética durante las dos últimas centurias, sino que parecía situado en las antípodas, sobre todo cuando esa experiencia era la de lo sublime, donde la excepcionalidad se extremaba. Pero el objeto común ante el que nos sitúa Korsmeyer, de pequeño e irrisorio como es, deviene ruin, grosero incluso, como lo es, desde luego, el universo de los productos de desecho, los mayores incitadores del asco para la autora, junto a todo aquello que viola los códidos fundamentales de higiene (Korsmeyer, 2011: 
30-38). Con Korsmeyer descendemos, por tanto, un peldaño más en la escala, ya de por sí descendida, de lo mundano, que sólo ignoramos, como hacemos en general con los útiles domésticos, y llegamos a lo inmundo, donde el desprecio y la desatención derivan en asco y, éste, a su vez, en terror, que es lo que acaban provocando los desechos, en los que por no haber, de lo inferiores que son, ni siquiera hay ya utilidad. De ahí que lo sublime correspondiente sea un sublime envilecido o encanallado, un sublime sin traza alguna ya de altura o de nobleza, donde es posible ver el reverso de lo sublime ilustrado. Ello explicaría el nombre que le atribuye Korsmeyer, «the sublate» -«lo depuesto» (2011: 131)-, para indicar así su condición de sublime inverso o regresivo ${ }^{33}$.

Lo decisivo para nosotros es que, por bajo y mezquino que resulte aquello que activa el sentimiento, la trascendencia sigue estando presente; una trascendencia, eso sí, bastante particular, a juzgar por el relato de Korsmeyer. Según cuenta la autora, guiada por la acepción química del término (Contesi, 2012: 115), lo que sucede en lo sublime convencional es que una sustancia pasa de estado sólido a gaseoso sin pasar antes por el líquido, mientras que en lo sublime inverso, el cambio, igual de directo, es de gaseoso a sólido. El primer proceso lo asocia metafóricamente Korsmeyer, ya en el plano estético, a la transformación que experimenta el sujeto, como ser córporeo y terrenal, a ser etéreo y elevado, al tomar conciencia de su superioridad espiritual frente al objeto que lo amedrenta con sus grandes dimensiones; el segundo proceso, a la recuperación de toda su esencia material y tangible, al descenso existencial por tanto, de ese ser devenido espíritu, cuando al contacto con el objeto repugnante, se sabe llamado a un destino de muerte primero y descomposición posterior. El denotante en ambos casos, explica Korsmeyer, es la superación del sujeto por un agente externo -honorable en el primer caso e infame en el segundo, añadimos nosotros- que despierta la emoción y, con ella, la conciencia de muerte, que es igual de intensa y reveladora en las dos situaciones, igual de aterradora; pero esa muerte es considerada mera destrucción en lo sublime como puro sublime y desintegración en lo sublime inverso, o reducción de una existencia noble a organismo infecto y pútrido (Korsmeyer, 2011:

33 Para la traducción, nos basamos en el ámbito de la termodinámica, donde la «sublimación inversa o regresiva», en tanto proceso inverso a la sublimación sin más, es llamada también «deposición». 
134). A través del miedo al que lleva el asco, lo sublime regresivo acaba provisto así también de contenido; miedo que al darle hondura reflexiva a la experiencia, debería hacerla figurar dentro de la que hemos llamado versión «fuerte» de lo sublime. Sin embargo, la misma Korsmeyer nos hace saber que, a diferencia de lo sublime en sentido estricto, lo sublime regresivo puede darse igualmente en muy pequeñas y sutiles dosis (2011: 135). Ello supone que el asco -en el que se centra la esteta-, pero sobre todo el miedo derivado de él -y el que a nosotros nos interesa- se verían aminorados en pro del asombro y la fascinación, a los que alude de modo expreso la autora cuando se refiere a lo sublime ${ }^{34}$, por lo que también en este caso arribamos a la versión «débil» de esta forma de experiencia.

\section{CONCLUSIÓN}

Queda demostrado que la experiencia estética de lo sublime tiene cabida en una estética aparentemente refractaria a lo grandioso y espiritual, y proclive al mismo tiempo a lo insignificante y terrenal, como es la estética de lo cotidiano; la tiene, incluso sin que el objeto responsable de la experiencia renuncie a su estatuto de objeto común, sin que sea transportado a la esfera artística -y, de ese modo, desnaturalizado-, como sucede en Leddy, pero sin que pase tampoco inadvertido, como en Haapala. Este objeto no sólo no pierde su naturaleza ordinaria y funcional, su pequeñez, como quiere Saito, sino que la extrema y eso le confiere un sentido adicional a ojos del sujeto que lo percibe; lo inviste de la trascendencia que siempre hubo en lo sublime. Sólo que esa trascendencia no nace en este caso del miedo o del terror, del sobresalto, como en la experiencia normalizada de lo sublime, pues el objeto ha disminuido ostensiblemente de tamaño y ya no apunta «hacia arriba»; nace de otro tipo de respuesta afectiva, más sosegada como el asombro, que también estuvo ahí, desde el principio -al menos, desde el siglo XVIII-, en la teorización de esta experiencia, aunque luego cayera en el olvido; asombro, admiración, embeleso, actitud estética en definitiva, ante aquello que rompe el esquema de la funcionalidad adaptándose soberbiamente a ella y transmite así valores de primer orden como la autenticidad y fidelidad a lo que uno es, valores del «aquí abajo», de los que da buena cuenta el héroe de Ortega.

Un sublime así es un sublime, no tanto venido a menos, como pulido o

34 «The fear underlying the sublime is transmuted into awe and exaltacion» (2011: 134). 
relajado, un sublime pálido, como aparece en Schopenhauer, o regresivo, como en Korsmeyer, pero un sublime que sigue siendo, pese a todo, sublime; que hace ver la grandeza de lo pequeño sin quebrantar su pequeñez, la de lo cotidiano en su misma cotidianeidad; el sublime que enseña, dice Ortega, que para quien lo pequeño no es nada, no es grande lo grande (2004b: 756).

REFERENCIAS BIBLIOGRÁFICAS:

Brady, E.: The Sublime in Modern Philosophy. Aesthetics, Ethics and Nature. Cambridge: Cambridge University Press, 2013.

Burke, E.: De lo sublime y de lo bello, trad. y estudio preliminar de Menene Gras Balaguer. Madrid: Tecnos, 2010 [1757].

Contesi, F.: «Savoring Disgust: the Foul and the Fair in Aesthetics» en British Journal of Aesthetics, 52 (1), 2012, pp. 113-116.

Dowling, Ch.: «The Aesthetics of Daily Life» en British Journal of Aesthetics, 50 (3), 2010, pp. 225-242.

Forsey, J.: «Appraising the Ordinary. Tension in Everyday Aesthetics» en Proceedings of the European Society for Aesthetics, 5, 2013a, pp. 237-245.

Forsey, J.: The Aesthetics of Design. Oxford: Oxford University Press, 2013b.

Haapala, A.: «On the Aesthetics of the Everyday: Familiarity, Strangeness and the Meaning of Place» en Light, A. y Smith, J. M. (eds): The Aesthetics of Everyday Life. Nueva York: Columbia University Press, 2004, pp. 39-55.

Heidegger, M.: Sein und Zeit, Frankfurt: Klostermann, 1977 [1927].

Johnson, D. B.: «The Postmodern Sublime: Presentation and its Limits» en Costelloe, T. M. (ed.): The Sublime from Antiquity to the Present. Cambridge: Cambridge University Press, 2012, pp. 118-131.

Kant, I.: Crítica del juicio, ed. y trad. de Manuel García Morente. Madrid: Espasa Calpe, 2001 [1790].

Keltner, D. y Haidt, J.: «Approaching Awe, a Moral, Spiritual an Aesthetic Emotion» en Cognition and Emotion 17(2), 2003, pp. 297-314.

Korsmeyer, C.: Savoring Disgust. The Foul and the Fair in Aesthetics. Oxford: Oxford University Press, 2011.

Leddy, T.: «Experience of Awe: an Expansive Approach to Everyday Aesthetics» en Contemporary Aesthetics Journal 13, 2015. 
Leddy, T.: The Extraordinary in the Ordinary. The Aesthetics of Everyday Life. Ontario: Broadview Press, 2012.

Murcia Serrano, I.: «Ortega y Gasset y la metamorfosis de la categoría estética de lo sublime» en Romero de Solís, D. y Murcia Serrano, I. (coords.): En ningún lugar. El paisaje y lo sublime. Sevilla: Universidad de Sevilla, 2015, pp. 351-379.

Ortega y Gasset, J.: «Arte de este mundo y del otro» en Obras completas. Madrid: Santillana/Fundación Ortega y Gasset/Centro de Estudios Ortguianos, 2004a (1911), tomo I, pp. 434-450.

Ortega y Gasset, J.: «Meditaciones del Quijote» en Obras completas. Madrid: Santillana/Fundación Ortega y Gasset/Centro de Estudios Orteguianos, 2004b [1914], tomo I, pp. 745-825.

Saint Girons, B.: Lo sublime, trad. de Juan Antonio Méndez. Madrid: Antonio Machado Libros, 2008.

Saito, Y.: Everyday Aesthetics. Oxford: Oxford University Press, 2007.

Saito, Y.: «The Aesthetics of Weather» en Light, A. y Smith, J. M. (eds.): The Aesthetics of Everyday Life. Nueva York: Columbia University Press, 2005, pp. 156-176.

Schopenhauer, A.: El mundo como voluntady representación, trad. de Eduardo Ovejero y Maury. México: Porrúa, 1987 [1818].

Stellar, J. et al.: «Self-Transcendent Emotions and Their Social Functions: Compassion, Gratitute and Awe Bind us to Others through Prosociality» en Emotion Review 9(3), 2017, pp. 200-207.

Trías, E.: Lo bello y lo siniestro. Barcelona: Ariel, 2001.

María Jesús Godoy Domínguez es profesora contratada doctora del departamento de Estética e Historia de la Filosofía, de la Universidad de Sevilla.

Lineas de investigación:

Estética contemporánea, Estética y cultura de masas, Estética y estudios de género, y Estética de los afectos.

Publicaciones recientes:

- «A propósito del arte abstracto: ¿Arte puro e insensible?», Estudios Filosóficos, Vol 67, Núm. 194. (2018), 363-379.

- «Negatividad y recepción estética: las emociones difíciles a la luz del pensamiento dialéctico de Adorno», Contrastes. Revista Internacional de Filosofía., 23 (2018), 111-126.

Dirección electrónica: godoydom@us.es 